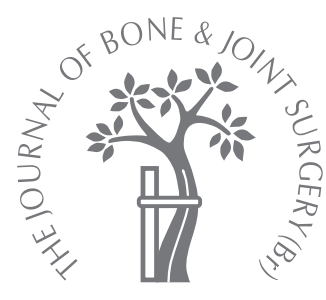

\title{
The culture of articular chondrocytes in hydrogel constructs within a bioreactor enhances cell proliferation and matrix synthesis
}
M. Akmal,
A. Anand,
B. Anand,
M. Wiseman,
A. E. Goodship,
G. Bentley

From the Institute of Orthopaedics, Stanmore, England

\section{Wiseman, PhD, Research Fellow \\ A. E. Goodship, PhD, MRCVS, Professor of \\ Musculoskeletal Science In. Bentley, MBBS, MCh, FRCS, Emeritus Professor of Orthopaedics \\ Institute of Orthopaedics, Royal National Orthopaedic Hospital, Brockley Hill, Stanmore, Middlesex HA7 4LP UK.}

M. Akmal, MBBS, BSc, FRCS(Orth and Tr), Consultant Orthopaedic Surgeon Department of Orthopaedics and Trauma, St. Mary's Hospital, London W2 1NY, UK.

A. Anand, MBBS, BSc, Foundation year 1 Trainee Barnet Hospital, Barnet, Hertfordshire EN5 3DL, UK

B. Anand, MBBS, BSc, Senior House Officer, Orthopaedics Charing Cross Hospital, London W6 8RF, UK.

Correspondence should be sent to Dr M. Akmal; e-mail: mo.akmal@st-marys.nhs.uk

C2006 British Editorial Society of Bone and Joint Surgery doi:10.1302/0301-620X.88B4 $16498 \$ 2.00$

$J$ Bone Joint Surg $[\mathrm{Br}]$ 2006;88-B:544-53.

Received 11 March 2005;

Accepted after revision

6 December 2005

\begin{abstract}
Bovine and human articular chondrocytes were seeded in $2 \%$ alginate constructs and cultured for up to 19 days in a rotating-wall-vessel (RWV) and under static conditions. Culture within the RWV enhanced DNA levels for bovine chondrocyte-seeded constructs when compared with static conditions but did not produce enhancement for human cells. There was a significant enhancement of glycosaminoglycans and hydroxyproline synthesis for both bovine and human chondrocytes. In all cases, histological analysis revealed enhanced Safranin-O staining in the peripheral regions of the constructs compared with the central region. There was an overall increase in staining intensity after culture within the RWV compared with static conditions. Type-II collagen was produced by both bovine and human chondrocytes in the peripheral and central regions of the constructs and the staining intensity was enhanced by culture within the RWV. A capsule of flattened cells containing type-I collagen developed around the constructs maintained under static conditions when seeded with either bovine or human chondrocytes, but not when cultured within the RWV bioreactor.
\end{abstract}

There is growing interest in the development of tissue-engineered repair systems for cartilage which involve the implantation of autologous chondrocytes into the sites of defects. ${ }^{1-6}$ Cells derived from the patient and expanded in culture, may be seeded into a suitable threedimensional scaffold and further processed in vitro to induce the production of new tissue, which is then implanted. ${ }^{7}$ The choice of the scaffold material and the nature of the in vitro processing of the resultant constructs influences the formation of neo-tissue and the ultimate efficacy of the repair.

Non-woven, fibrous, three-dimensional meshes of polylactic acid and polyglycolic acid have been the most widely investigated materials. ${ }^{8,9}$ While these scaffolds have been used with some degree of success, it is often difficult to achieve a uniform cell density during seeding. The resulting scaffolds have limited mechanical properties before the new tissue has formed and therefore, an extended period of culture prior to pre-implantation is required. An alternative approach has involved the use of hydrogels, such as alginate, which are formed around the chondrocytes. ${ }^{5,10,11}$ These give a uniform cell density throughout the construct ${ }^{10,12}$ and have improved mechanical properties when compared with mesh fibrous systems, ${ }^{4,8,9}$ thus facilitating earlier implantation.
For full-depth repair, tissue-engineered constructs are required to span the entire depth of the tissue, which may be several millimetres. ${ }^{13}$ In order to maintain cellular viability within a construct of this thickness, effective delivery of bioactive molecules and nutrients in vitro is required. Previous studies have reported heterogeneous cellular responses within large three-dimensional alginate constructs because cells in the central region have a reduced metabolism. ${ }^{12}$ This leads to disorganised tissue formation in conditions of standard static culture. In extreme cases, this may give a significant loss of viability in the central region because of the poor availability of nutrients. ${ }^{14}$ The use of alginate constructs prepared at low concentrations improves mass transport, but compromises their mechanical integrity. ${ }^{12}$ An alternative approach is to enhance transport of the nutrient mass by subjecting the construct to a dynamic fluid environment within a bioreactor system.

Rotating-wall-vessel (RWV) bioreactors are a family of commercially available systems, which have the same fluid dynamic operating principles. They provide rotation about a horizontal axis, which is characterised by the colocation of particles of different sedimentation rates and extremely low fluid shear stress and turbulence. ${ }^{8,9}$ The constructs remain sus- 
pended in a constantly moving body of nutrient medium and are therefore, subjected to fresh medium all the time. A number of studies have shown that the formation of neocartilage and the subsequent mechanical integrity of the constructs may be enhanced during culture within the RWV compared with those in conditions of static culture, or maintained within a turbulent flow environment, such as a mixer flask. ${ }^{8,9,15}$ However, most of these studies have used non-woven fibrous scaffolds with high porosity rather than alginate hydrogel constructs. The environment for mass transport within these two systems is different. Moreover, in previous studies chondrocytes isolated from young bovine cartilage were used. ${ }^{8,9}$ These cells are known to have enhanced metabolic and proliferative rates when compared with adult human chondrocytes. Our study tests the hypothesis that culture within a RWV bioreactor enhances proliferation and synthesis of a cartilage-specific matrix by bovine and human chondrocytes seeded in alginate constructs.

\section{Materials and Methods}

Isolation of chondrocytes. Bovine cartilage was harvested from the metacarpophalangeal joints of six 18-month-old calves. Specimens of human tissue were obtained from limbs following above-knee amputation at the Royal National Orthopaedic Hospital, Stanmore, United Kingdom. All the knees were clinically healthy, free from tumour and had not previously been exposed to radio- or chemotherapy. Human tissue was obtained from eight patients with a mean age of 23 years (17 to 29). The cartilage was obtained aseptically within six hours of collection of the tissue from the operating theatre. The study was approved by the relevant Local Ethics Committee.

The full-thickness sections of articular cartilage were collected in a culture dish containing Dulbecco's minimal essential medium (DMEM), supplemented with 20\% (v/v) fetal calf serum (FCS), 2 mM L-glutamine, $20 \mathrm{mM}$ HEPES, $100 \mathrm{unit} / \mathrm{ml}^{-1}$ of penicillin, $100 \mu \mathrm{g} / \mathrm{ml}^{-1}$ of streptomycin and $50 \mu \mathrm{g} / \mathrm{ml}^{-1}$ of L-ascorbic acid (DMEM + 20\% FCS; all Gibco, Paisley, United Kingdom). The slices of cartilage were diced finely and incubated at $37^{\circ} \mathrm{C}$ for one hour in $\mathrm{DMEM}+20 \% \mathrm{FCS}+700$ unit $/ \mathrm{ml}^{-1}$ of pronase $(\mathrm{BDH}$ Merck Ltd, Poole, United Kingdom) and for 16 hours at $17^{\circ} \mathrm{C}$ in DMEM $+20 \%$ FCS +100 unit $/ \mathrm{ml}^{-1}$ of collagenase type-XI (Sigma, Poole, United Kingdom). The supernatant containing the released chondrocytes was passed through a sieve with a pore size of $70 \mu \mathrm{m}$ (Falcon, Oxford, United Kingdom), washed twice in DMEM $+20 \%$ FCS and finally re-suspended in DMEM $+20 \%$ FCS. The cell number and viability were determined using a haemacytometer and staining with Trypan Blue.

Formation and culture of the alginate construct. For the preparation of alginate constructs, the cell suspension was adjusted to $20 \times 10^{6}$ cells $/ \mathrm{ml}^{-1}$ for bovine and human chondrocytes. The cell suspensions were added to $4 \%$ alginate (Keltone LV; Kelvo Nutrasweet, Poole, United Kingdom) in
Earle's balanced salt solution (EBSS; Gibco) to give a final concentration of $10 \times 10^{6}$ cells $/ \mathrm{ml}^{-1}$ in $2 \%(\mathrm{w} / \mathrm{v})$ alginate. The cell/alginate suspension was slowly expressed through a 22-gauge needle into a solution containing $100 \mathrm{mM}$ $\mathrm{CaCI}_{2}$ in DMEM. The resultant beads were approximately spherical in shape with a diameter of approximately $3 \mathrm{~mm}$.

One group of constructs was transferred to a tissueculture dish containing $50 \mathrm{ml}$ of medium and incubated at $37^{\circ} \mathrm{C} / 5 \% \mathrm{CO}_{2}$ for up to 19 days. This group represented the static culture conditions with all beads lying in a single layer on a flat surface. An equal number of constructs were cultured in the $50 \mathrm{ml}$ chamber of an RWV bioreactor (Synthecon, RCCS Model, Bereldange, Luxembourg). This ensured that there were equal amounts of medium per cell in both groups. A maximum of 200 constructs was used to minimise frequent collisions between the constructs during rotation of the culture chamber. The vessel was sealed and attached to the rotator base of the RWV, which was maintained at $37^{\circ} \mathrm{C} / 5 \% \mathrm{CO}_{2}$ for up to 19 days. The initial speed of rotation was set to 6 to $8 \mathrm{rpm}$ and, when necessary, adjusted to higher speeds to ensure that the constructs did not collide with each other or the edges of the vessel. The culture media for both groups were replaced every three days. Representative constructs were removed for subsequent analysis at selected time points.

Biochemical analysis. Ten replicates of ten beads with bovine cells and five replicates of ten beads with human cells were taken at each time point for biochemical analysis. The chondrocyte/alginate gels were disrupted and digested by incubation in papain digest buffer, a solution containing $55 \mathrm{mM}$ sodium citrate (BDH), $150 \mathrm{mM}$ sodium chloride (BDH), $5 \mathrm{mM}$ cysteine hydrochloride (Sigma), $5 \mathrm{mM}$ EDTA $(\mathrm{BDH})$ and 0.56 units $/ \mathrm{ml}^{-1}$ of papain (Sigma) at $60^{\circ} \mathrm{C}$ for 24 hours.

The total DNA was determined using the Hoechst method. ${ }^{16,17}$ Calf thymus DNA in a solution of $55 \mathrm{mM}$ sodium citrate and $150 \mathrm{mM}$ sodium chloride $+0.4 \%(\mathrm{v} / \mathrm{v})$ sodium dedecyl sulphate was used for preparation of the standard curve, ranging from 0 to $20 \mu \mathrm{g} / \mathrm{ml}^{-1}$. Aliquots (100 $\mu \mathrm{l})$ of standards or samples were added to appropriate wells in a fluorimetric well-plate. To each well-plate were added $100 \mu \mathrm{l}$ of Hoechst $33258\left(1 \mu \mathrm{g} / \mathrm{ml}^{-1}\right)$ in $55 \mathrm{mM}$ sodium citrate and $150 \mathrm{mM}$ sodium chloride and the plates were read on a fluorimeter (Fluoroskan Ascent; LabSystems, Oxford, UK) with a $355 \mathrm{~nm}$ excitation filter and emission at 460 $\mathrm{nm}$.

Measurement of the total sulphated glycosaminoglycans (GAG) in the chondrocyte cultures was performed using the 1,9-dimethylMethylene Blue (DMB) dye method, ${ }^{18}$ which had been modified for use with an alginate system at a $\mathrm{pH}$ of 1.5. ${ }^{19}$ Aliquots of a papain-digested sample and a solution containing $21 \mu \mathrm{g} / \mathrm{ml}^{-1}$ of $\mathrm{DMB}$ and $2 \mathrm{mg} / \mathrm{ml}^{-1}$ of sodium formate and $0.5 \%(\mathrm{v} / \mathrm{v})$ ethanol in distilled water ( $\mathrm{pH} 1.5)$ were added to individual wells of a multi-well plate. The absorbance at $595 \mathrm{~nm}$ was determined using a microplate reader (Bio-Rad Ltd, Hemel Hempstead, United 
Table I. Details of primary antibodies used for immunolocalisation (DSHB, Developmental Studies Hybridoma Bank, University of lowa, lowa; Type-X collagen antibody donated by Dr Alvin Kwan, Department of Biochemistry, Cardiff University, United Kingdom)

\begin{tabular}{cllll}
\hline Antigen & Primary antibody & Dilution & Source & Positive control \\
\hline $\begin{array}{c}\text { Collagen } \\
\text { Type-I }\end{array}$ & Col-I & $1: 100$ & Sigma & Bovine tendon \\
Type-II & CIICl & $1: 2$ & DSHB & Bovine cartilage \\
Type-X & $\mathrm{MC7}$ & $1: 100$ & Donated & Bovine cartilage \\
\hline
\end{tabular}

Kingdom). The concentration of GAG was determined by comparison with a chondroitin-6-sulphate standard curve (0 to $100 \mu \mathrm{g} / \mathrm{ml}^{-1}$, Sigma).

The hydroxyproline content in the alginate beads was measured using an oxidation assay ${ }^{20}$ which was run in a Cobas Bio centrifugal analyser (Roche Products Ltd., Welwyn Garden City, United Kingdom) at $40^{\circ} \mathrm{C}$. The assay involved the oxidation of the amino acid hydroxyproline in the samples by chloramine T. The chromogens formed (pyrrole and pry-2-carboxylic acid) were coupled with p-dimethylaminobenzaldehyde to produce a chromophore, the absorbance of which could be measured at $570 \mathrm{~nm}$. Standard curves were used to determine the concentration of hydroxyproline in the sample range 0 to $100 \mu \mathrm{mol} / \mathrm{l}^{-1}$.

Histological examination and immunolocalisation. Representative chondrocyte/alginate constructs collected for histological and immunohistochemical analysis were fixed in a solution containing $2 \%$ paraformaldehyde in $0.1 \mathrm{M} \mathrm{NaCaCo}$ at $\mathrm{pH}$ 7.4. The samples were dehydrated through a series of ethanol concentrations, cleared with xylene and embedded in paraffin wax. Sections were cut at a thickness of $8 \mu \mathrm{m}$ using a sledge microtome and mounted on to glass slides.
For histological examination, the sections were stained using iron haematoxylin and Safranin-O to visualise cells and GAG-rich extracellular matrix. The streptavidin biotin-immunoperoxidase method was used for the immunolocalisation of collagen type-I, -II and -X, using the antibodies detailed in Table I. The sections were rehydrated and incubated in $200 \mu \mathrm{l}$ of hydrogen peroxide in $12 \mathrm{ml}$ of methanol to block the activity of endogenous peroxidase. The peroxidase-blocked sections were subsequently pretreated in $0.1 \%(\mathrm{w} / \mathrm{v})$ trypsin (Sigma) and $0.1 \%(\mathrm{w} / \mathrm{v})$ $\mathrm{CaCI}_{2}$ in distilled $\mathrm{H}_{2} \mathrm{O}$ at $37^{\circ} \mathrm{C}$ for ten minutes. After pretreatment they were washed in tap water and soaked in trisbuffered saline (TBS) $(0.05 \mathrm{M}$ TRIS, $0.15 \mathrm{M} \mathrm{NaCI}$ at $\mathrm{pH}$ 7.6). To suppress non-specific binding of IgG, the sections were blocked with normal rabbit serum (Dako A/S, Glostrup, Denmark), diluted 1:5 in TBS for 20 minutes. The sections were then incubated with the selected primary antibody for 30 minutes at room temperature. They were washed with TBS, biotinylated rabbit anti-mouse secondary antibody (Dako A/S) was applied and they were incubated at room temperature for 30 minutes and then rinsed. Streptavidin-biotin complex (Dako A/S) was applied for 30 minutes, followed by the liquid substrate solution containing $0.7 \mathrm{mg} / \mathrm{ml}^{-1}$ of $3^{\prime} 3^{\prime}$-diaminobenzidine tetrahydrochloride, $0.7 \mathrm{mg} / \mathrm{ml}^{-1}$ of urea hydrogen peroxide and Tris buffer $0.006 \mathrm{M}$ (Sigma) was prepared. The sections were counterstained with Harris's haematoxylin, washed in tap water and differentiated in acid alcohol before mounting and visualisation.

Statistical analysis. The comparison between the biochemical data obtained from static and RWV cultures was performed using the unpaired Student's $t$-test. A p value of $<0.05$ represented a statistically significant difference.

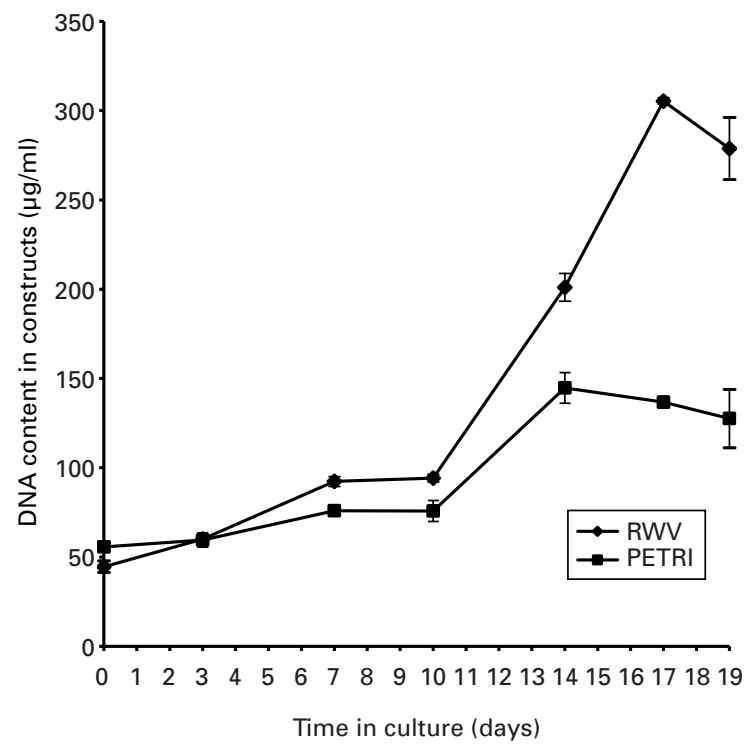

Fig. 1a

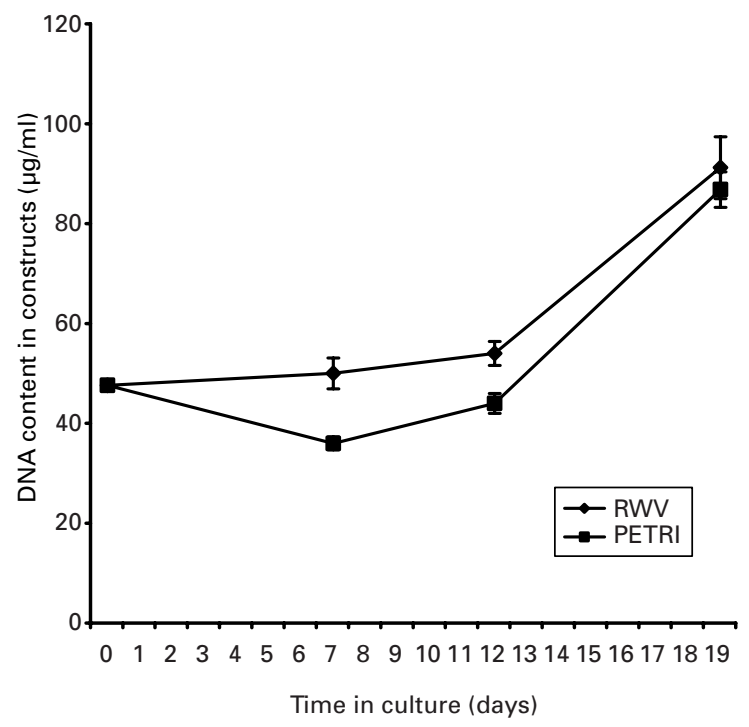

Fig. 1b

Graphs showing the DNA content of a) bovine chondrocyte-seeded alginate beads and b) human chondrocyte-seeded alginate beads, cultured for 19 days in a dynamic rotating wall vessel (RWV) bioreactor and a static petri culture dish. 


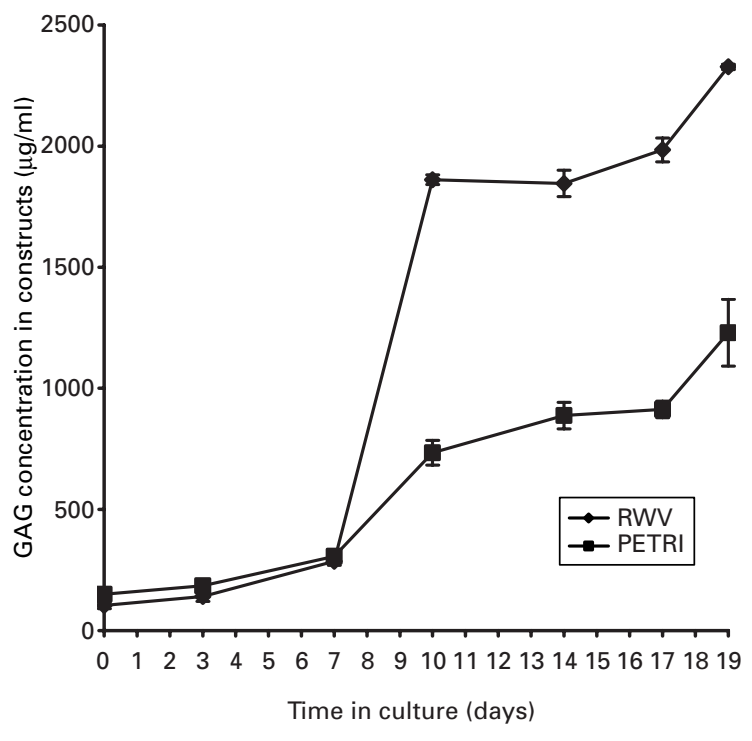

Fig. 2a

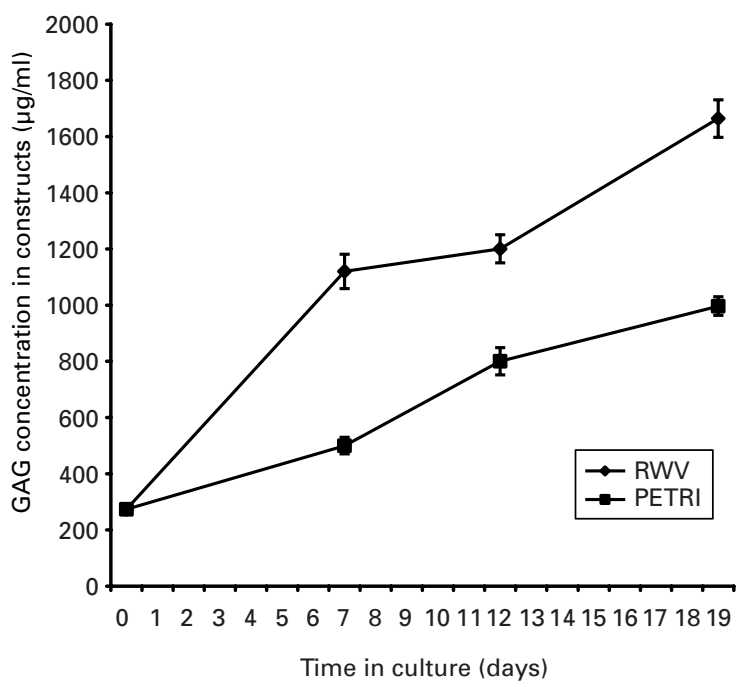

Fig. $2 b$

Graphs showing the total GAG content of a) bovine chondrocyte-seeded alginate bead constructs and b) human chondrocyte-seeded alginate bead constructs, cultured for 19 days in a rotating wall vessel (RWV) bioreactor and a static petri culture dish.

\section{Results}

Biochemical analysis. The DNA content of bovine chondrocyte-seeded alginate constructs cultured for up to 19 days in static conditions and within the RWV is shown in Figure 1a. The initial DNA concentration was $48.2 \mu \mathrm{g} / \mathrm{ml}^{-1}$ of alginate. DNA values for the bovine chondrocyte-seeded constructs increased slowly during the initial stages of culture, reaching a level by day seven of $73.0 \mu \mathrm{g} / \mathrm{ml}^{-1}$ and 92.2 $\mu \mathrm{g} / \mathrm{ml}^{-1}$, in the static and RWV cultures, respectively. Thereafter, the DNA values increased rapidly, with the increase being greatest in the RWV specimens. Accordingly, on day 14 , the concentrations were $144 \mu \mathrm{g} / \mathrm{ml}^{-1}$ for static cultures and $201 \mu \mathrm{g} / \mathrm{ml}^{-1}$ for RWV cultures, the differences being statistically significant $(\mathrm{p}=0.01)$. The concentrations continued to increase in the RWV culture up to day 17 , but decreased in the static culture (Fig. 1a).

Corresponding DNA values within the alginate constructs which had been seeded with human chondrocytes are shown in Figure $1 \mathrm{~b}$. The initial concentration of DNA was $47.6 \mu \mathrm{g} / \mathrm{ml}^{-1}$ of alginate. There was little change in the DNA concentration in the RWV cultured constructs up to day 12. The corresponding static cultures showed a decreased DNA concentration after seven days in culture compared with the initial values. Subsequently, the concentrations increased, so that by day 19 the values were 86.8 $\mu \mathrm{g} / \mathrm{ml}^{-1}$ and $91.2 \mu \mathrm{g} / \mathrm{ml}^{-1}$ for the static and RWV cultures, respectively. The differences between the two cultures were not statistically significant $(\mathrm{p}=0.01)$.

GAG values within alginate constructs seeded with bovine chondrocytes and cultured for up to 19 days are given in Figure $2 \mathrm{a}$. The initial values measured within the constructs were $127 \mu \mathrm{g} / \mathrm{ml}^{-1}$ of alginate. They increased slowly during the first week of culture, but there was no significant difference between the static condition $\left(307 \mu \mathrm{g} / \mathrm{ml}^{-1}\right)$ and the RWV $\left(285 \mu \mathrm{g} / \mathrm{ml}^{-1}\right)$ at day seven. Thereafter, the rate of increase was greatly enhanced in the RWV cultured constructs, compared with the static model. By day 19, the values were $1.23 \mathrm{mg} / \mathrm{ml}^{-1}$ and $2.33 \mathrm{mg} / \mathrm{ml}^{-1}$ for the static and RWV conditions, respectively. The difference in the GAG levels between the two systems was highly significant at day ten and thereafter $(\mathrm{p}=0.06)$.

The corresponding GAG values for alginate constructs seeded with human chondrocytes are illustrated in Figure $2 \mathrm{~b}$. The concentration in the constructs at the start of the experiment was $274 \mu \mathrm{g} / \mathrm{ml}^{-1}$ for both groups and increased steadily throughout the culture period for both culture conditions, although the rate of increase was significantly greater in the RWV cultured constructs. By day 19, the GAG values were $996 \mu \mathrm{g} / \mathrm{ml}^{-1}$ and $1664 \mu \mathrm{g} / \mathrm{ml}^{-1}$ for static and RWV cultures, respectively $(\mathrm{p}=0.005)$.

The content of hydroxyproline within the constructs seeded with bovine chondrocytes are given in Figure $3 \mathrm{a}$. The initial hydroxyproline measured was $80 \mu \mathrm{g} / \mathrm{ml}^{-1}$. The concentration gradually increased during the week in culture. There was a rapid increase in the rate of production in both culture conditions from day seven. At day 14, the content measured $800 \mu \mathrm{g} / \mathrm{ml}^{-1}$ and $1100 \mu \mathrm{g} / \mathrm{ml}^{-1}$ for the static and RWV conditions, respectively. The difference in concentration between the two culture conditions was significant at day 14 and thereafter $(\mathrm{p}=0.01)$.

The corresponding values for human chondrocytes are illustrated in Figure $3 \mathrm{~b}$. The hydroxyproline concentration was $70 \mu \mathrm{g} / \mathrm{ml}^{-1}$ for both groups at day zero and increased steadily in both culture conditions, although the rate of 


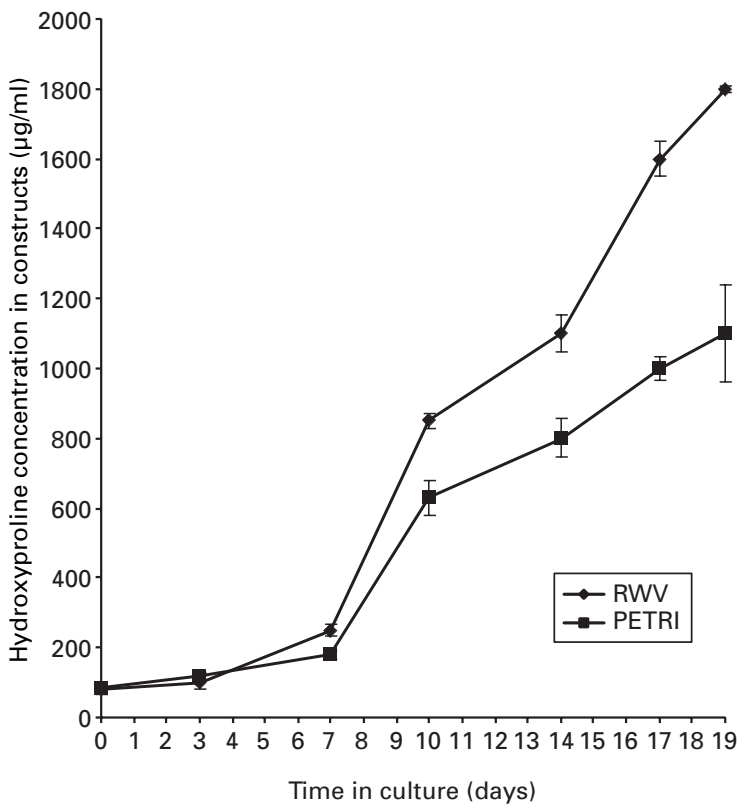

Fig. 3a

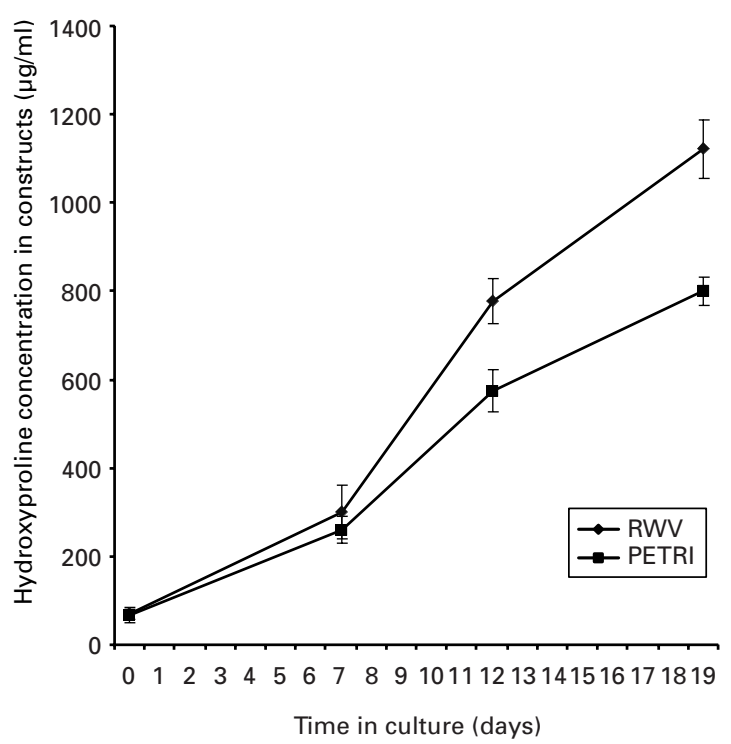

Fig. 3b

Graphs showing the total hydroxyproline content of a) bovine chondrocyte-seeded alginate bead constructs and b) human chondrocyte-seeded alginate bead constructs, cultured for 19 days in a rotating wall vessel (RWV) bioreactor and a static petri culture dish.

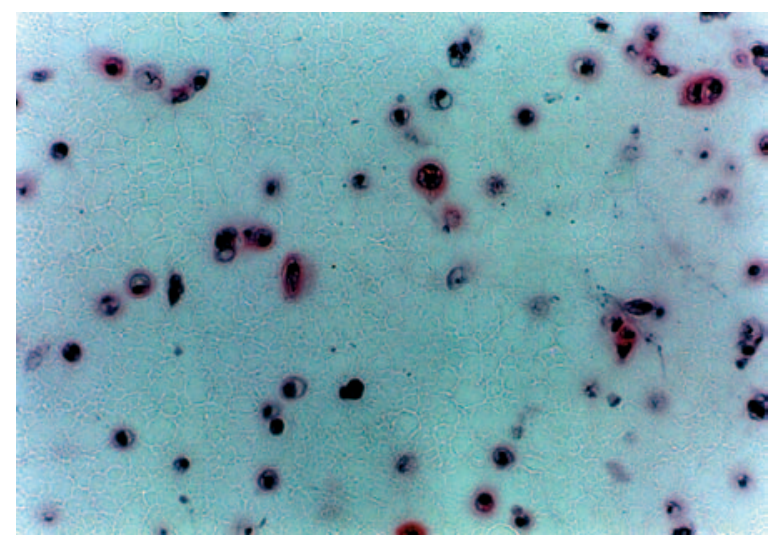

Fig. $4 a$

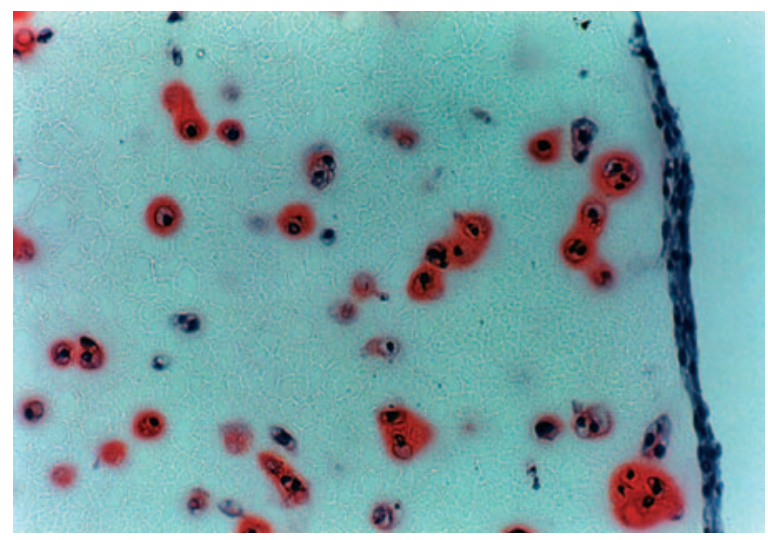

Fig. 4c

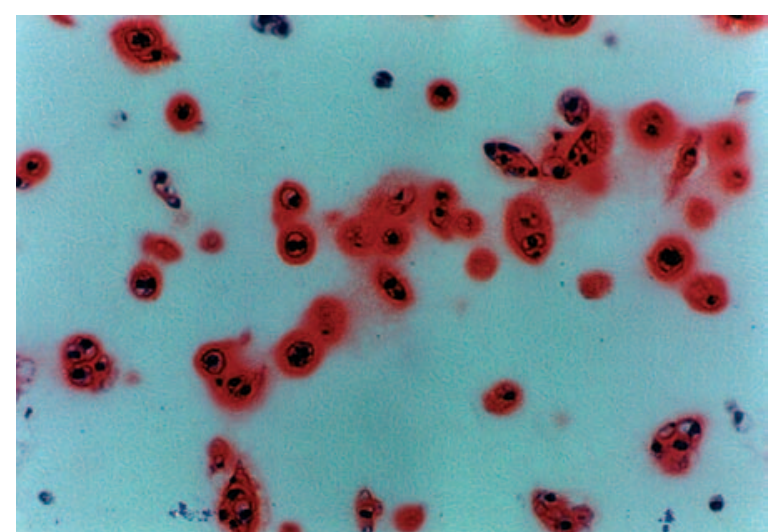

Fig. $4 \mathrm{~b}$

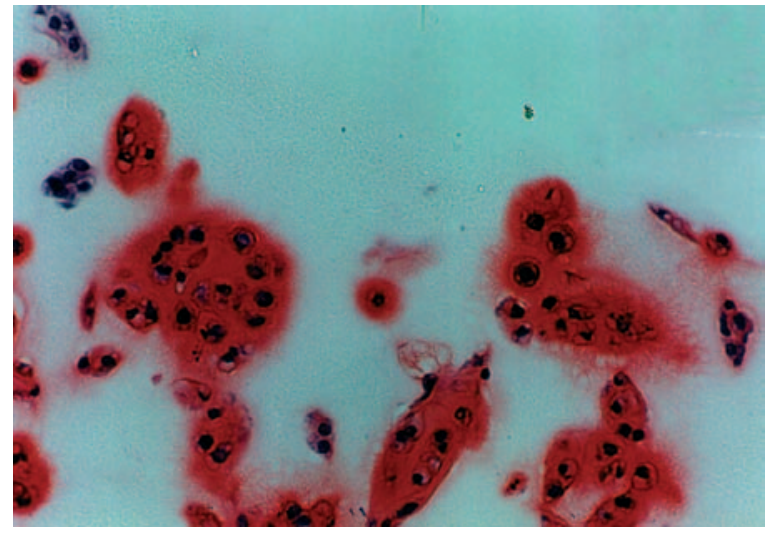

Fig. 4d

Photomicrographs of bovine chondrocytes in alginate beads at day 14 in Safranin-O stain (x 20 magnification). a) in static culture, centre of the bead; b) in rotating wall vessel (RWV) bioreactor, centre of the bead; c) in static culture, peripheral edge of the bead; d) in RWV bioreactor, peripheral edge of the bead. 


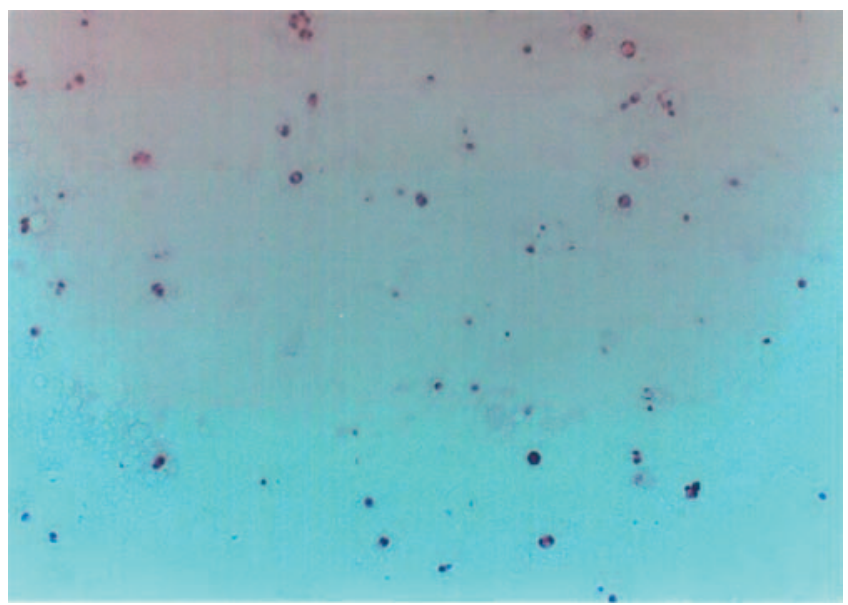

Fig. 5a

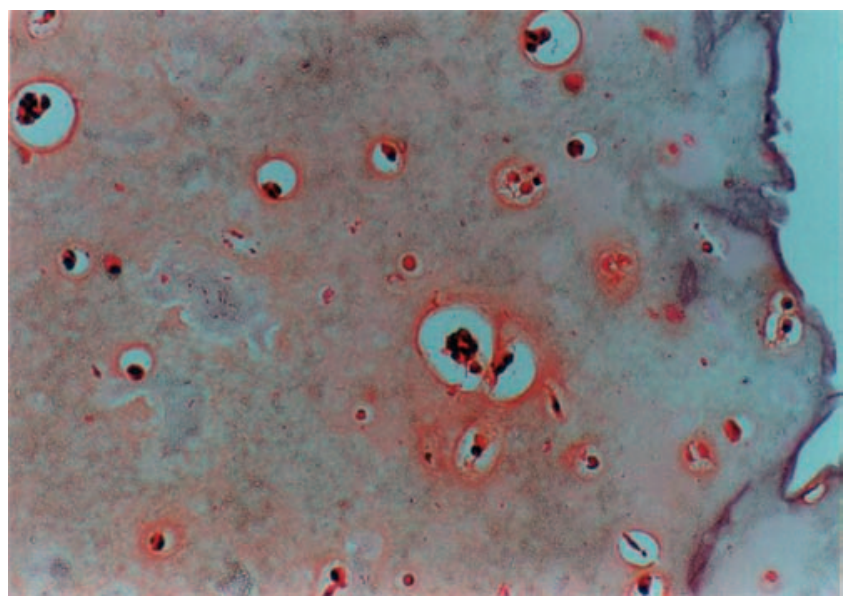

Fig. $5 c$

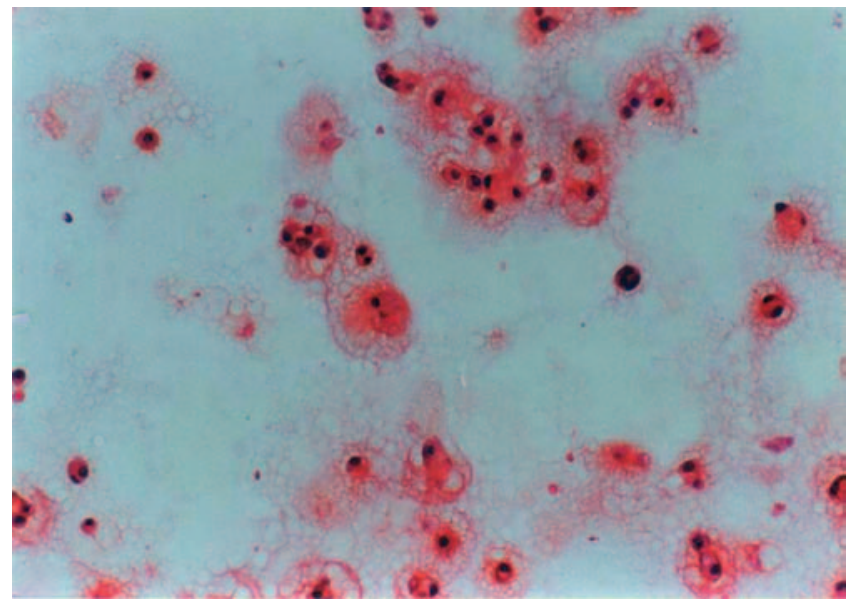

Fig. $5 b$

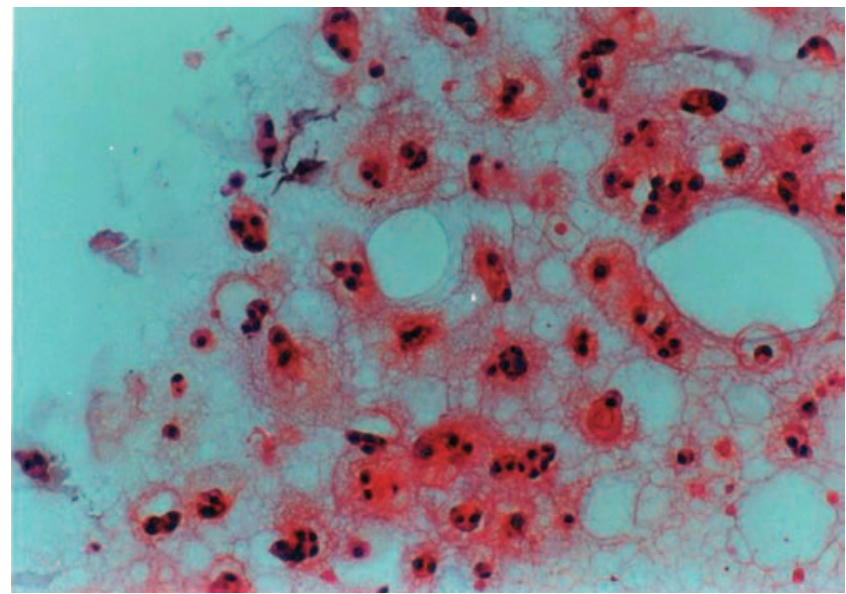

Fig. $5 d$

Photomicrographs of human chondrocytes in alginate beads at day 14 in Safranin-O stain (x 20 magnification). a) in static culture, centre of the bead; b) in rotating wall vessel (RWV) bioreactor, centre of the bead; c) in static culture, peripheral edge of the bead and d) in RWV bioreactor, peripheral edge of the bead.

increase was significantly greater in the RWV cultured from day seven onwards. By day 19 , the values were $800 \mu \mathrm{g} / \mathrm{ml}^{-1}$ and $1122 \mu \mathrm{g} / \mathrm{ml}^{-1}$ for static and RWV cultures, respectively $(\mathrm{p}=0.01)$.

Histological examination and immunolocalisation. Figure 4 shows the histological findings in the central (Figs $4 a$ and b) and peripheral (Figs $4 \mathrm{c}$ and $\mathrm{d}$ ) regions of bovine chondrocyte-seeded alginate constructs, maintained in static culture (Figs $4 \mathrm{a}$ and c) or within the RWV (Figs $4 \mathrm{~b}$ and d), for 14 days. In the peripheral region of constructs maintained in static culture, the cells were well dispersed, in groups of up to four and had a rounded morphology. A pericellular region of GAG-rich extracellular matrix, approximately five to $10 \mu \mathrm{m}$ in thickness surrounded most cell groups, as indicated by staining with Safranin O (Fig. 4c). At the extreme periphery, however, a layer of flattened cells was present which formed a capsule around the construct. By contrast, at the centre of the construct no clumps of cells were observed. Safranin-O staining was weak and present only in the immediate pericellular space (Fig. 4a). When cultured in the RWV, an increase in the intensity and extent of Safranin-O staining was noted in all regions when compared with static conditions (Figs $4 \mathrm{~b}$ and d). The three regions of matrix (pericellular, interterritorial and territorial) were identifiable and in some locations, neighbouring clumps of interterritorial matrix had combined. Moreover, cell clusters often consisted of ten or more cells in the peripheral region (Fig. 4d) and up to four cells in the central region (Fig. 4b). The cells at the periphery were larger and had enhanced Safranin-O staining compared with those in the central region. No capsule of flattened cells was present surrounding the constructs cultured in the RWV bioreactor.

The corresponding histological images for human chondrocytes in alginate constructs are shown in Figure 5. In the static cultures, diffuse Safranin-O staining was observed within the peripheral region with a slight increase in stain- 


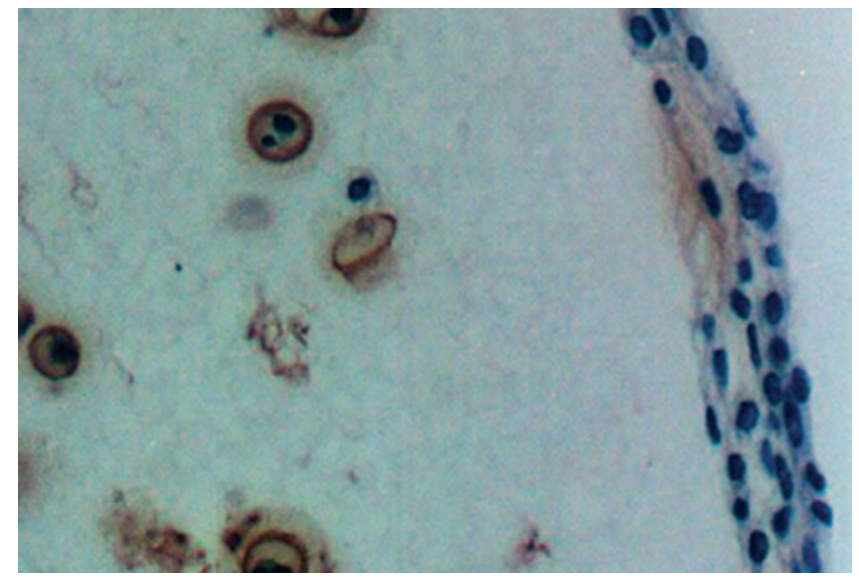

Fig. 6a

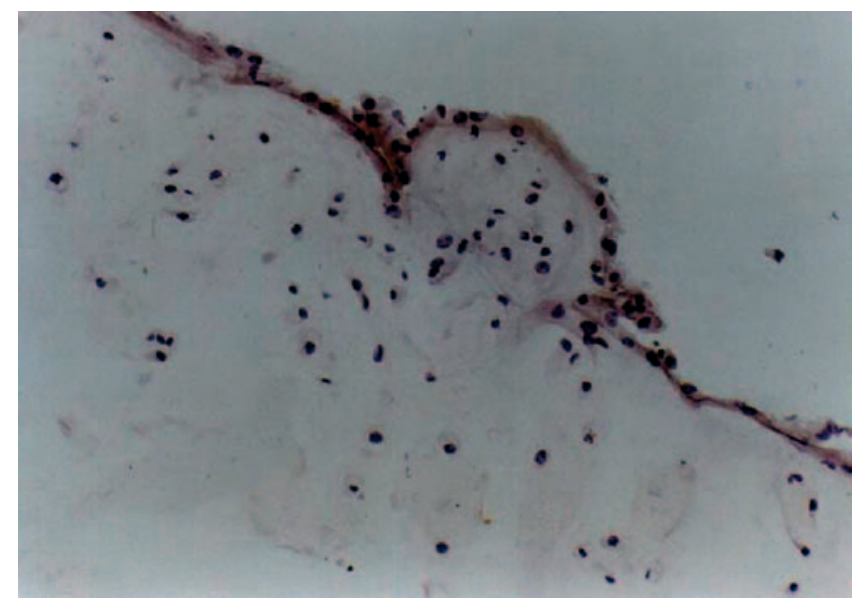

Fig. 6c

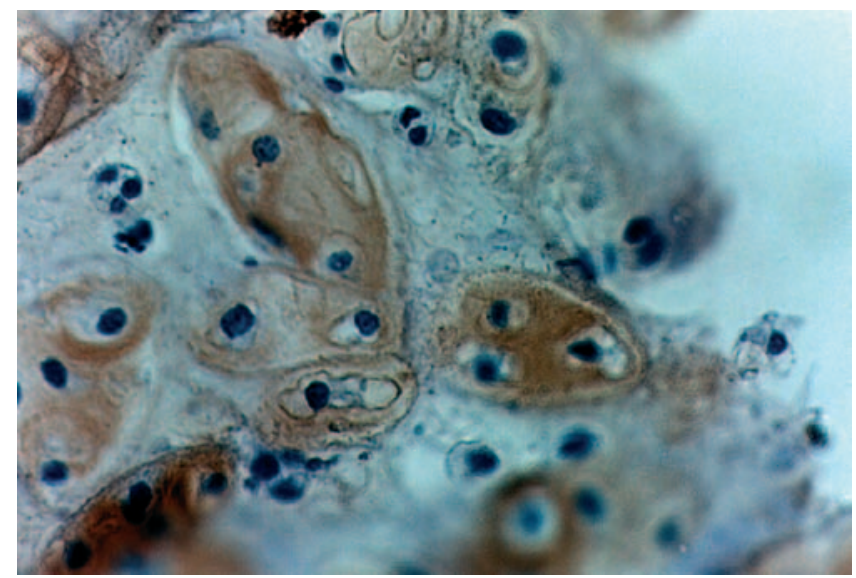

Fig. 6b

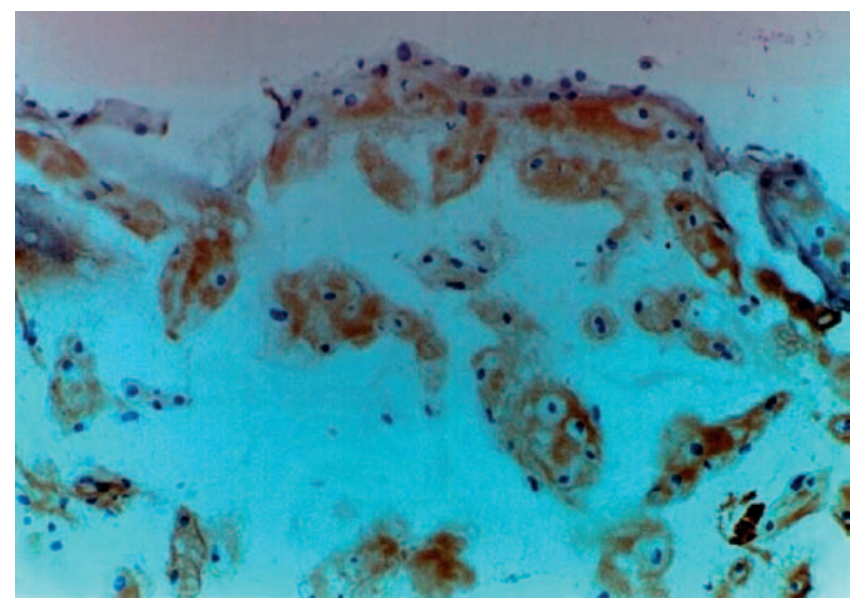

Fig. 6d

Photomicrographs showing collagen type-Il in a) bovine static culture; b) bovine rotating wall vessel (RWV); c) human static culture and d) human RWV.

ing intensity around the chondrocytes (Fig. 5c). These showed a large variation in size and were distributed singly or in pairs. In some cases, flattened cells were present at the extreme periphery of the construct. Figure 5a shows that human cells at the centre were associated with only a small amount of extracellular matrix and had minimal cell division. Culture within the RWV bioreactor enhanced Safranin-O staining in both the peripheral and central regions, compared with static culture (Figs $5 \mathrm{~b}$ and $5 \mathrm{~d}$ ) and the staining was more cell-associated. An increase in the size of cell clusters was also noted, with groups of up to four cells present in both the peripheral and central regions. All the cells had a rounded morphology and the capsule of flattened cells was absent.

Figure 6 shows collagen type-II immunolocalisation within constructs seeded with bovine (Figs $6 \mathrm{a}$ and b) and human (Figs 6c and d) chondrocytes cultured in static conditions (Figs 6a and c) or within the RWV bioreactor (Figs $6 \mathrm{~b}$ and $\mathrm{d}$ ). Bovine chondrocytes cultured in static conditions had limited type-II staining, primarily associated with rounded cells at the periphery of the construct (Fig. 6a). The cells at the surface of the construct with a flattened morphology did not express collagen type-II (Fig. 6a). In the RWV culture the staining for collagen type-II was of greater intensity and distributed more extensively throughout the construct when compared with static conditions. In static cultures, human chondrocytes stained poorly for collagen type-II (Fig. 6c), while staining was more intense and widely distributed within the cultures in the RWV bioreactor (Fig. 6d).

Type-I collagen was expressed only by cells with a flattened morphology, which formed a capsule surrounding both bovine and human chondrocyte-seeded constructs cultured in static conditions (Fig. 7). No type-I collagen expression was observed for constructs maintained in the RWV bioreactor (data not shown since staining did not appear). Type-X collagen staining was not detected in any constructs, although the positive control (growth plate cartilage) had intense staining in the calcified cartilage region (data not shown). 


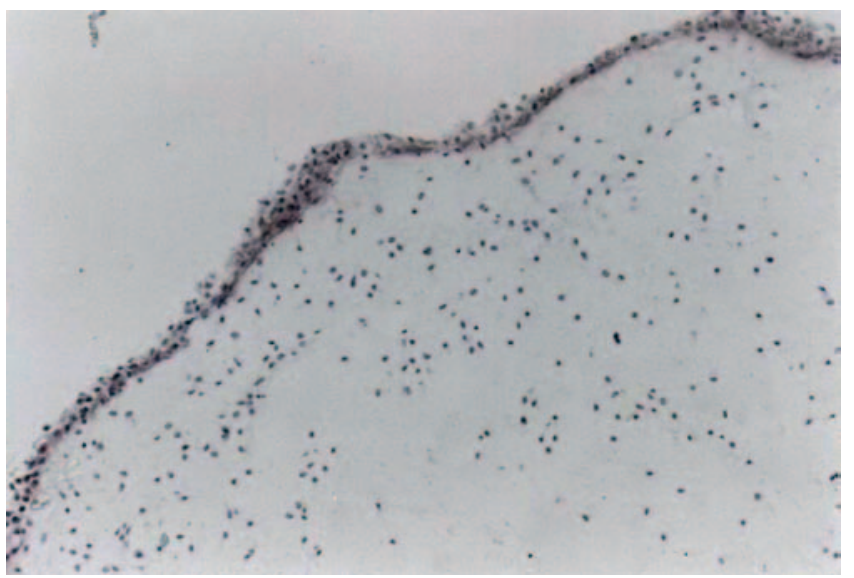

Fig. 7a

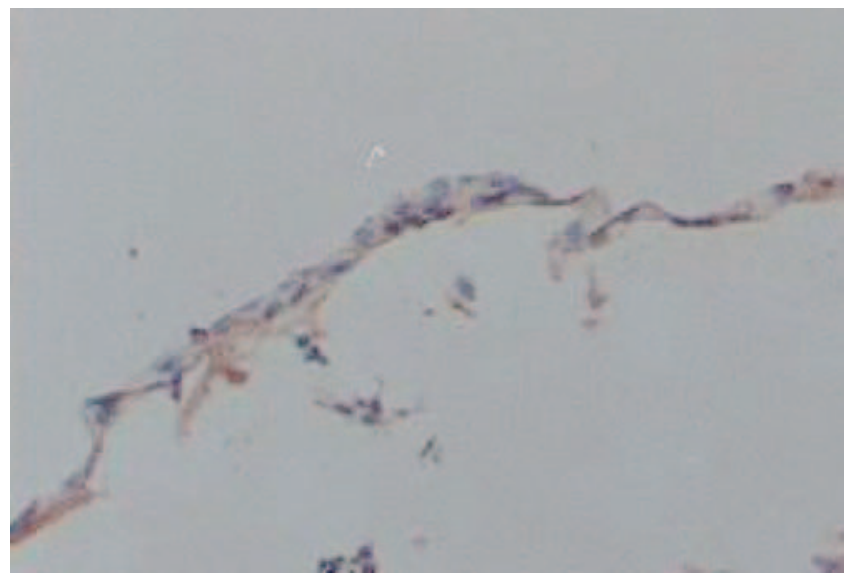

Fig. 7b

Photomicrographs showing collagen type-l staining in a) bovine static culture and b) human static culture.

\section{Discussion}

Our aim was to investigate whether culture within the RWV bioreactor enhanced proliferation and synthesis of cartilage-specific matrix components by bovine and human chondrocytes seeded in alginate constructs.

These have been shown to offer an attractive strategy for tissue engineering, both for the expansion of articular chondrocytes and for use as scaffold materials. ${ }^{5,10,11}$ High-cell densities and the material properties associated with alginate impose limitations to mass transport. The use of dynamic devices, such as the RWV bioreactor, which improve diffusional gradients may enhance mass transport of nutrients to cells.

The DNA content within the constructs at a particular time in the culture is determined by the initial seeding density of cells and the synthesis and degradation of DNA during necrosis and/or apoptosis. For bovine cells, the DNA levels increased during the culture period, suggesting that cell proliferation was occurring. These findings were confirmed by histological analysis, which revealed the presence of clusters of cells formed by cell proliferation. The use of an RWV bioreactor for culturing chondrocytes resulted in significantly higher levels of DNA within constructs containing bovine cells (Figs $4 \mathrm{~b}$ and $4 \mathrm{~d}$ ), compared with static cultures, suggesting an enhancement of cell proliferation within the bioreactor. These findings are in agreement with those of other studies. ${ }^{8,14,15}$ The histological data support these findings, the largest cell clusters being present within constructs maintained in the RWV. By contrast, culture within the RWV did not induce marked alteration in the DNA content for human chondrocyte-seeded constructs when compared with static culture (Fig. 1b). During the first seven days in culture, the DNA levels decreased in constructs containing human chondrocyte cultured in static conditions. This phenomenon presumably reflected the degradation of DNA associated with cell death at the centre of the construct. The reasons for the initial decline in cell numbers are unknown, but may be related to a delay in acclimatisation of the cells to the new environment. Culture within the RWV bioreactor may reduce this effect since DNA levels remained static throughout the initial 14 days of culture. Between days 14 and 19, cell proliferation resulted in an increase in the DNA content for constructs cultured in both conditions, resulting in the formation of small cell clusters in the peripheral region of the construct.

Histological analysis showed the presence of a capsule of flattened cells around the surface of the constructs in both bovine and human cells when cultured under static conditions. The capsule was absent when constructs were cultured in the RWV. This capsule was presumably formed by cells on the surface of the beads which attached and continued to divide in a monolayer-like fashion, as well as from the release of cells from the extreme periphery of the construct, which attached, flattened and subsequently proliferated to form a multilayer. In the RWV dynamic culture system however, cells at the extreme periphery do not form a multilayer, which may have been because of their inability to maintain a purchase to the surface since the beads were in constant circular motion. Thus, while total DNA values may be similar in human chondrocyte-seeded constructs cultured in both conditions, the increases in DNA values within the RWV were exclusively related to the formation of cell clusters within the constructs rather than the formation of a surface multilayer.

The difference in response between the bovine and human chondrocytes may reflect an inherent difference in the proliferative capacity of human cells compared with other species, which has been discussed previously. ${ }^{21}$ Accordingly, mitogenic or cell-survival factors released in an autocrine or paracrine fashion could play a greater role in controlling cellular function within bovine-seeded, compared with human-seeded constructs.

The level of sulphated GAG within alginate constructs was measured as an indicator of chondrocyte-mediated elabora- 
tion of a proteoglycan-rich matrix. The GAG content recorded in human chondrocyte-seeded constructs was comparable with that expressed by the bovine cells in both culture systems (Fig. 2). The present data show that GAG synthesis was enhanced by culture within the RWV bioreactor, compared with static conditions, for both bovine and human chondrocytes (Fig. 2). However, the increase in staining intensity appeared to be similar throughout the construct and therefore the heterogeneity of matrix elaboration between the peripheral and central regions of the construct was maintained. It appears therefore, that the alterations in the hydrodynamic environment, provided by culture within the RWV bioreactor, were sufficient to enhance mass transport within the constructs, predominantly by convective mechanisms, but that this process was not able to completely overcome the fundamental nutrient gradients associated with three-dimensional alginate constructs, which led to a heterogeneous metabolic response and subsequent matrix elaboration. Moreover, greater utilisation of nutrients by cells at the periphery of the construct may have further increased the heterogeneity within the RWV reactor, compared with that in static culture conditions, as has been suggested recently. ${ }^{22}$

The level of hydroxyproline within the constructs was a marker for collagen production by the chondrocytes. The data presented showed changes similar to those of GAG production, whereby hydroxyproline synthesis for both bovine and human chondrocytes was enhanced by culture within the RWV bioreactor compared with static conditions. The immunohistochemical results showed that the chondrocytic phenotype was maintained in the threedimensional scaffold constructs as indicated by the presence of collagen type-II and absence of collagen type-I within them. Collagen type-II, in conjunction with aggrecan, both specific markers for chondrocyte activity, has an important role in defining the mechanical integrity of articular cartilage. The enhanced staining for collagen type-II (Fig. 6) in the RWV culture conditions confirmed the stimulatory potential of this system for collagen as well as proteoglycan, when compared with static conditions. Significantly, collagen type-I, a marker for fibrocartilaginous or fibroblastic phenotype, was identified in the cellular capsule which formed around the periphery of alginate constructs containing both bovine and human cells and cultured under static conditions. This suggested that a proportion of chondrocytes maintained in static conditions showed modulation to a fibroblastic phenotype, a phenomenon not seen in any of the specimens cultured in the RWV bioreactor. Collagen type-X, which is a marker for hypertrophic change in the chondrocytes, was not detected in any of the specimens, suggesting that terminal differentiation was not induced by the culture conditions within the time period investigated.

The enhanced proliferation and metabolic activity of chondrocytes cultured in the RWV beads may not only be the result of improved nutritional effects, but may also reflect the effects of altered biomechanical forces acting on the constructs. The RWV moves in a circular motion, rotat- ing the culture medium and beads within. This is likely to create both centripetal and centrifugal forces, as well as shear stresses on the surface of the beads as they move continually through the medium. These biomechanical forces may play an important role in directly influencing chondrocytic activity, but were not the focus of our study.

Our findings support the hypothesis that culture within the RWV bioreactor enhances cell proliferation by both bovine and human chondrocytes. The response of human chondrocytes was less pronounced than that of bovine chondrocytes. GAG and hydroxyproline synthesis by both bovine and human chondrocytes in alginate constructs was enhanced in both cell types, but in human cells there was a relatively greater matrix synthetic response per cell. In addition, the phenotype of the cells within the RWV was more stable than in static conditions with absence of either dedifferentiation or terminal differentiation. The RWV environment improved the fundamental nutrient gradients associated with three-dimensional alginate constructs, by enhancing mass nutrient transfer and thereby improving cell proliferation and matrix elaboration deep within the construct. Although there remained some spatial heterogeneity within the construct, even in its present form it can be used to significantly improve in vitro cell culture for the purposes of tissue engineering of articular cartilage using three-dimensional hydrogel constructs. The possibilities of using dynamic culture devices, combined with growth factor or techniques of molecular biology in the future may further improve tissue engineering of articular cartilage.

We are grateful for the help of Dr J. Pringle and Mr M. Kayser (Department of Histopathology, Institute of Orthopaedics) with the histological analysis and for the assistance of the Bone Tumour Unit at the Royal National Orthopaedic Hospital with supply and collection of human specimens. Our study was funded in part by the Engineering and Physical Sciences Research Council, Action Research and the Wishbone Trust, UK.

No benefits in any form have been received or will be received from a commercial party related directly or indirectly to the subject of this article.

\section{References}

1. Bentley G, Greer RB. The fate of chondrocytes in endochondral ossification in the rabbit. J Bone Joint Surg [Br] 1970;52-B:571-7.

2. Brittberg M, Lindahl A, Nilsson A, et al. Treatment of deep cartilage defects in the knee with autologous chondrocyte transplantation. N Engl J Med 1994;331:889-95.

3. Grande DA, Pitman MI, Peterson L, Menche D, Klein M. The repair of experimentally produced defects in rabbit articular cartilage by autologous chondrocyte transplantation. J Orthop Res 1989;7:208-18.

4. Kawamura S, Wakitani S, Kimura T, et al. Articular cartilage repair: rabbit experiments with a collagen gel-biomatrix and chondrocytes cultured in it. Acta Orthop Scand 1998;69:56-62.

5. Paige KT, Cima LG, Yaremchuk MJ, et al. De novo cartilage generation using calcium alginate-chondrocyte constructs. Plast Reconstr Surg 1996;97:168-78.

6. Vacanti CA, Langer R, Schloo B, Vacanti JP. Synthetic polymers seeded with chondrocytes provide a template for new cartilage formation. Plast Reconstr Surg 1997;88:753-9.

7. Benya PD, Shaffer JD. Dedifferentiated chondrocytes reexpress the differentiated collagen phenotype when cultured in agarose gels. Cell 1982;30:215-24.

8. Freed LE, Hollander AP, Martin I, et al. Chondrogenesis in a cell-polymer-bioreactor system. Exp Cell Res 1998;240:58-65.

9. Freed LE, Vunjak-Novakovic G, Langer R. Cultivation of cell-polymer cartilage implants in bioreactors. J Cell Biochem 1993;51:257-64.

10. Lee DA, Reisler T, Bader DL. Expansion of chondrocytes for tissue engineering in alginate beads enhance chondrocytic phenotype compared to conventional monolayer techniques. Acta Orthop Scand 2003;74:6-15. 
11. van Susante JL, Buma P, van Osch GJ, et al. Culture of chondrocytes in alginate and collagen carrier gels. Acta Orthop Scand 1995;66:549-56.

12. Häuselmann HJ, Fernandes RJ, Mok SU, et al. Phenotypic stability of bovine articular chondrocytes after long-term culture in alginate beads. J Cell Sci 1994;107: 17-27.

13. Breinan HA, Minas T, Hsu HP, et al. Autologous chondrocyte implantation in canine model: change in composition of reparative tissue with time. J Orthop Res 2001;19:482-92.

14. Vunjak-Novakovic G, Martin I, Obradovic B, et al. Bioreactor cultivation conditions modulate the composition and mechanical properties of tissue-engineered cartilage. J Orthop Res 1999;17:130-8.

15. Martin I, Obradovic B, Treppo B, et al. Modulation of the mechanical properties of tissue engineered cartilage. Biorheology 2000;37:141-7.

16. Rago R, Mitchen J, Wilding G. DNA fluorometric assay in 96-well tissue culture plates using Hoechst 33258 after cell lysis by freezing in distilled water. Anal Biochem 1990;191:31-4.
17. Rao J, Otto WR. Fluorimetric DNA assay for cell growth estimation. Anal Biochem 1992;207:186-92.

18. Farndale RW, Buttle DJ, Barrett AJ. Improved quantitation and discrimination of sulphated glycosaminoglycans by use of dimethylmethylene blue. Biochim Biophys Acta 1986;883:173-7.

19. Enobakhare BO, Bader DL, Lee DA. Quantification of sulfated glycosaminoglycans in chondrocyte/alginate cultures, by use of 1,9-dimethylmethylene blue. Anal Biochem 1996;243:189-91.

20. Ho KC, Pang CP. Automated analysis of urinary hydroxyproline. Clin Chim Acta 1989; 185:191-6.

21. Almqvist KF, Wang L, Wang J, et al. Culture of chondrocytes in alginate surrounded by fibrin gel: characteristics of the cells over a period of eight weeks. Ann Rheum Dis 2002;60:781-90.

22. Heywood HK, Sembi PK, Lee DA, Bader DL. Cellular utilisation determines viability and matrix distribution profiles in chondrocyte-seeded alginate constructs. Tissue Engineering 2004;10:1467-79. 